ISSN: $1980-055 X$

\title{
TÉCNICAS COMPUTACIONAIS, MODELOS E ESCALAS NOS ES- TUDOS DA ATMOSFERA: REFLEXÕES INICIAIS
}

\author{
Lucí Hidalgo Nunes ${ }^{1}$
}

\begin{abstract}
RESUMO
O artigo discute como as inovações podem contribuir para o progresso ou retrocesso na ciência e como a falta de conhecimento prévio do pesquisador quanto às técnicas empregadas podem comprometer o produto final do estudo. Enfatiza o uso de modelos em termos de suas contribuição e limitação atual para o conhecimento da atmosfera.
\end{abstract}

Palavras-chave: ciências atmosféricas, modelos, escala.

\section{COMPUTATIONAL TECHNIQUES, MODELS AND SCALES FOR THE ATMOSPHERIC STUDIES: INITIALS REFLEXIONS}

\begin{abstract}
The paper discusses the ways in which innovations can contribute to the progress or regress in the Science and how the lack of previous knowledge of techniques by the researcher can compromise the final product of a given study. It emphasizes the use of models in terms of their contribution and current limitation for the knowledge of the atmosphere.
\end{abstract}

Key-words: Atmospheric Sciences, models, scale.

\section{Introdução}

O avanço recente no conhecimento dos fenômenos atmosféricos em suas interações dinâmicas guarda relação direta e indissociável com o desenvolvimento da computação, vista com potencial para se transformar em uma linguagem universal para a construção do conhecimento voltado ao planejamento. Ela reveste-se de uma aura de modernidade e facilidade, sendo assim bastante atraente e, via de regra, tomada como ferramenta de simples utilização, flexível e que responderia a todos os problemas que se colocam nos estudos dos fenômenos atmosféricos.

${ }^{1}$ Geógrafa, Profa. Dra., Departamento de Geografia, Instituto de Geociências/UNICAMP - R. João Pandiá Calógeras, 51 CP 6152, 13.083-970, Campinas, SP - luci@ige.unicamp.br 
Porém, para chegar-se à automação, é preciso um trabalho prévio abstrativo. As imensas facilidades para o emprego de técnicas matemáticas por meio de computador advindas do progresso da cibernética, a conseqüente queda de preços em computadores pessoais de pequeno porte e a proliferação de programas com ambiente amigável e que, portanto, facilitam seu emprego, mascaram, todavia, um fato importante e perigoso: a falta de conhecimento de informações científicas que devem anteceder o seu uso. O enorme corpo de dados a ser analisado pelo pesquisador interessado em conhecer os processos que levam às diferenças temporo-espaciais dos fenômenos atmosféricos em escalas diversas e a pretensa simplicidade em se empregar técnicas sofisticadas que levariam ao conhecimento desses mecanismos de forma rápida, simples e precisa constitui-se, ao mesmo tempo, em algo atraente e pernicioso, pois, conforme alertado por Cole e King (apud Netwig-Silva, 1978), a possibilidade de uma ciência existir é determinada não pelo o que, mas pelo como; não pelo assunto, mas pelo método. E o método não deve ser confundido com a técnica, e esta deve ser familiar ao pesquisador para que seu uso - seguindo o método proposto, condizente com os objetivos da pesquisa - possa de fato contribuir para que a investigação alcance resultados eficazes.

Jean Ulmo (apud Morais, 1981) lembra que "Os instrumentos prolongaram e ampliaram os sentidos do homem (...)os computadores multiplicaram as possibilidades da sua inteligência e ampliaram seu pensamento". Mas o computador é um meio artificial de pensamento, um mero executor, cujo funcionamento segue a ordem que se estabelece a partir da programação. $E$, conforme alertou Santos (1997), o sistema técnico segue um sistema de ações, normas e valores que traz embutido a intencionalidade nos seus procedimentos.

Nos estudos voltados para a avaliação das tendências recentes do clima, técnicas taxonômicas numéricas têm sido usadas para o estabelecimento de padrões de comportamento das variáveis climáticas no tempo e no espaço. Mas alguns dos instrumentos classificatórios mais recentes - e, portanto, vistos como mais modernos - são, na realidade, técnicas antigas "vestidas" de modernidade por programas computacionais. Esse fato inúmeras vezes não é detectado pelo profissional, por falta de conhecimento teórico básico mais aprofundado. Certamente o uso de instrumental moderno - especialmente computacional - não substitui nem atenua a necessidade de conhecimento teórico prévio. Pelo contrário, enfatiza-o.

Quanto a esse aspecto, deve-se lembrar que historicamente muitas ciências desenvolveram-se pela concepção idiográfica-monográfica, em que os fenômenos seriam encarados como únicos, decorrentes de suas localizações e individualizações no espaço, não se sujeitando as leis e princípios gerais. Isso relevou a um plano de menor importância o processo de construção teórica ou de generalização, que faz com que os fenômenos sejam encarados de forma nomotética, sujeitos às leis probabilísticas e princípios gerais. Para adaptar-se a uma tendência na Ciência de valorizar o conhecimento que pode ser matematizado e generalizado, disseminou-se o emprego de técnicas inicialmente de forma mais manual e, mais tarde, por uso de computadores, sem que muitas vezes houvesse um necessário conhecimento profundo delas.

No caso do estudo das condições da atmosfera, ainda que o seu conhecimento caracterize-se como empírico-formal, com análise de dados coleta- 
dos por medições racionalizadas pelas ciências formais, elas se encontram cada vez mais próximas das ciências hermenêuticas, dada a necessidade crescente de interpretação dos sinais que o homem inscreve no mundo à medida que se relaciona com o meio físico. O estudo dos fenômenos do clima adquire cada vez mais uma componente social, tendo em vista que o mesmo evento atinge os diferentes setores da sociedade de formas distintas, dadas as vulnerabilidades dos grupos humanos. Porém, a ciência ainda tem grande dificuldade em incorporar de forma equilibrada componentes físicos e sociais. Discutindo essa questão Nunes (2005, p.204) salienta que "o conteúdo científico de diversos sistemas tecnológicos é francamente dominado por aproximações derivadas das ciências naturais, subestimando ou até omitindo o peso de alguns dos componentes do sistema.".

Num mundo marcado por tantas transformações - do meio atmosférico, inclusive - o desenvolvimento da Ciência tem ocorrido, preponderantemente, pelo desenvolvimento de modelos que, na definição clássica de Haggett e Chorley (1975), vem a ser uma estruturação simplificada da realidade que apresentaria as características ou relações mais proeminentes. É interessante salientar que mesmo uma breve consideração histórica evidencia que o ser humano tem um desejo permanente de predizer acontecimentos. A habilidade em fazer previsões precisas nas civilizações antigas era uma forma de poder e dominação, estando circunscrita às elites. Recentemente, é um modo de obter vantagens econômicas e/ou tomar decisões em relação a desastres naturais iminentes.

Os modelos climáticos surgem para atender uma série de demandas parcialmente independentes, que visam descrever processos ocorrentes na natureza por meio de conjuntos de equações matemáticas com parametrização física dos eventos não capturados nas escalas do produto gerado pelos modelos, criando réplicas simplificadas do sistema natural, de maneira que causas e efeitos possam ser mais bem entendidos. Eles são constantemente realimentados com novos dados e corrigidos para melhor precisar a contribuição real de processos para as condições analisadas, e com essas incessantes validações são usados para predizer acontecimentos e para avaliar como teriam sido as condições pretéritas. Os modelos teriam por escopo responder perguntas do tipo: "o que ocorreria se...", tipo de indagação que não falta no estudo da atmosfera.

Modelos com variados graus de sofisticação têm sido desenvolvidos, lembrando que, em princípio, quanto maior suas resoluções, maior a aproximação com a realidade o que, em princípio, faz com que as escalas de mais detalhe tenham maior interesse prático. Porém, segundo Giorgi e Mearns (1991) e apenas considerando modelos de circulação geral, o tempo requerido para rodar esses modelos cresce, aparentemente, com a segunda potência do espaçamento de pontos da grade horizontal, tendo em vista a necessidade de memória para armazenamento e análise. Problemas de limitação de recursos computacionais são particularmente importantes no caso de modelos que requerem uma extensiva integração para alcançar o equilíbrio, largamente ampliado quando mais componentes são incorporadas.

Por falta de informações mais acuradas, por vezes é feito um exercício inócuo de estimar mudanças em escala local a partir de resultados de grande escala por meio de resoluções semi-empíricas para adequar as resoluções. Mais uma vez, o uso de ferramenta computacional sofisticada não substitui o conheci- 
mento de interações profundas e dinâmicas dos componentes ambientais, com ênfase no ajuste escalar - que mesmo assim nem sempre é possível, de acordo com a cobertura de dados - fator inexplicavelmente negligenciado em muitos estudos que partem de dados muito generalizados para retratar a variabilidade climática, intra e interanual, muito considerável na maioria dos regimes climáticos, inclusive aqueles prevalecentes no país. Porto-Gonçalves (2004, p. 33) sublinha que o ser humano - e, portanto, a ciência por ele produzida - acredita (...)poder fazer, sempre, com tudo e em todas as escalas, como se o que ocorre numa determinada escala fosse válido para qualquer escala e para o todo. Discutindo também a questão da escala, Castro (2000, p. 136) expõe que: (as escalas) "definem modelos espaciais de totalidades sucessivas e classificatórias e não uma progressão linear de medidas de aproximação sucessivas".

Outro ponto nevrálgico no desenvolvimento de modelos é sua condição de inicialização, dada pela condição do momento da atmosfera - um sistema parcialmente caótico e, com isso, muito sensível à condição inicial - com integração de equações no tempo com vistas às descrições da circulação atmosférica e de sua estrutura ou, dependendo do objetivo do modelo, predizer situações advindas das mudanças climáticas. Modelos que partem de condições de inicialização distintas podem chegar a cenários bastante discrepantes em termos da magnitude das situações previstas e em relação aos próprios cenários antevistos, por vezes apresentando situações contrastantes.

Dadas as características altamente dinâmicas e não lineares dos componentes da atmosfera, há que se ponderar que mesmo em uma situação virtualmente perfeita a predição mais longa incorre em erros, por mais que, dialeticamente, os modelos visem justamente eliminar a imprevisibilidade, a incerteza. Isso reforça a necessidade de indicação nos modelos do nível de confiança envolvido, sem o qual seria um exercício inócuo (BURROUGHS, 1997; GILES, 2000), e vincula-se ao exposto por Leff (2004, p.60): "O saber (...)tem afinidade com a incerteza e a desordem, com o campo do inédito, do virtual, dos futuros possíveis $(\ldots)^{\prime \prime}$.

Todas as fases do modelo - construção, compreensão, operacionalidade, teste e manutenção - necessitam extensivos recursos computacionais, cada vez mais ampliados, pois se até recentemente os modelos eram elaborados preponderantemente em escala global, cuja generalidade não possibilita a captura de feições importantes, atualmente está acontecendo um grande esforço para a produção de modelos regionais (downscale techniques), que agregam novas componentes. Certamente essa incorporação não deve decompor os constituintes do complexo sistema ambiental em partes a serem interligadas no sistema modelado por meio de formulações matemáticas, pois a totalidade não pode ser vista como mera soma das partes. Afinal, "As tendências (...)separadas de seus contextos, (...)também não são prognósticos acerca do desenvolvimento do todo sobre a base de análises e diagnósticos de suas partes" (ALTVATER, apud PORTO-GONÇALVES, op. cit). Ainda, nas palavras de Leff (op. cit, p.58): "O conhecimento, ao se fragmentar analiticamente para penetrar nos entes, separa o que organicamente está articulado(...)".

Dado o exposto, salienta-se que o momento demanda a familiarização do pesquisador com técnicas diversas, interações escalares e inovações na área computacional. Exige, sobretudo, um mergulho profundo na teoria, com re- 
conhecimento de que a incerteza, a indeterminação e a possibilidade integram a essência da complexidade inerente dos arranjos dinâmicos da atmosfera. Afinal, a racionalidade cognitivo-instrumental da modernidade impõe uma nova racionalidade (...)aberta à incerteza, ao risco, à diversidade e à diferença (Leff, op. cit), fato que vai de encontro a uma visão científica que busca uma unidade do conhecimento, desconsiderando as especificidades do lugar e do tempo.

O exercício de desenvolvimento dos modelos requer avanços computacionais para que, com base em um padrão de alterações dinâmicas geral, eles sejam sensíveis para capturar as especificidades das condições atmosféricas locais, em associação com os demais atributos físicos e com as modificações incessantes pela ação antropogênica. Implica, igualmente, no reconhecimento de que os mesmos componentes em contextos diversos têm pesos diferentes nos arranjos dinâmicos do ambiente, e que a quantificação de algumas variáveis menos concretas e que podem diferir consideravelmente em situações socioeconômicas e culturais distintas, apresenta enorme dificuldade em sua mensuração e incorporação nos modelos.

O avanço da modelagem é dirigido para a produção de modelos de maior resolução escalar, estando assim mais próximo do nível em que os fenômenos efetivamente acontecem. Eles teriam maior potencial para evidenciar o intercâmbio entre componentes físicas e sociais em seus arranjos espaciais, pois mesmo tendo em mente que as interações entre sociedade e natureza acontecem em escalas que vão dos níveis global ao local, tendências variadas, que refletem o modelo de desenvolvimento econômico e padrões de ocupação do espaço, se cristalizam em contextos socioambientais distintos, fator identificável somente em escalas mais refinadas (KATES, 2001; NUNES, 2002). Modelos com resolução mais fina também apresentam potencial (que, todavia, pode não ser necessariamente explorado) de focar mais nitidamente as organizações entre os componentes do sistema e os desequilíbrios eventuais que podem alterar o balanço interativo entre as forças compreendidas pelo sistema natural, contrariamente às forças sociais. Contudo, enfatiza-se mais uma vez que a complexidade do mundo real é de tal ordem que faz com que os modelos - que não são o mundo real, mas uma retratação simplificada dele e, por conseguinte, falhos por definição - não capturem todas as relações, tampouco a ordem hierarquizada e de magnitude da associação dinâmica dos seus componentes, o que traz embutido o fato de que a decisão perante os cenários que se colocam será sempre de ordem política que, por sua vez, refletirá os anseios de quem está no poder...

\section{Bibliografia Consultada}

BARROW, J.D. World within world - a journey to the edge of space and time. Oxford: Oxford University Press, 1990. 398 p.

BURROUGHS, W.J. Does the weather really matters? the social implications of climate change. Cambridge: Cambridge University Press, 1997. 230p.

CASTRO, I.E. de O problema da escala. In: CASTRO, I.E. de, COSTA, P.C. da, CORREA, R.L. (org.) Geografia: conceitos e temas. Rio de Janeiro: Bertrand do Brasil, 2000. Cap. p.4 117-140.

CHRISTOFOLETTI, A. Modelagem de sistemas ambientais. São Paulo: Edgard 
Blücher, 2000. 236p.

GILES, J. When doubt is a sure thing, Nature, v. 418, n.6897, p. 476-478, 2002.

GIORGI, F.; MEARNS, L.O. Approaches to the simulation of regional climate change: a review, Reviews of Geophysics, v.29, n.2., p. 191-216. 1991.

HAGGET, P: CHORLEY, R.J. Modelos físicos e de informação em geografia. Rio de Janeiro: Livros Técnicos e Científicos, 1975. 221p.

KATES, R.W. 2001. Nature-society interaction: understanding environmental and development together. In: The global change open science conference. Amsterdam, 2001. Abstracts... Amsterdam, 2001. p.6.

LEFF, E. Aventuras da epistemologia ambiental - da articulação das ciências ao diálogo de saberes. Rio de Janeiro: Garamond, 2004. 85p.

MORAIS, J.F.R. Ciência e tecnologia - introdução metodológica e crítica. São Paulo: Cortez \& Moraes, 1981. 181p.

NUNES, L.H. Aproximações sobre mudanças climáticas globais, Revista Terra Livre, v.1, n.18, p.179-184. 2002.

NUNES, L.H. Interações entre a atmosfera e a sociedade: em busca de novas perspectivas, Geografia, v.30, n.1, p.199-208. 2005.

PORTO-GONÇALVES, C.W. O desafio ambiental. Rio de Janeiro: Record, 2004. 179p.

SANTOS, M. A natureza do espaço. São Paulo: Hucitec, 1997. 308p.

NETWING-SILVA, B.C.N. 1978. Métodos quantitativos aplicados em geografia: uma introdução, Geografia, v.3, n.6, p. 33-73. 1978. 